\title{
Effect of P Addition on the Thermal Stability of Nanocrystalline Ni-Co-Fe-P Coatings
}

\author{
Pinqiang Dai1 ${ }^{1 *}$, Lvbo Lin ${ }^{1}$ \\ ${ }^{1}$ College of Materials Science and Engineering, Fuzhou University, Fuzhou, China \\ ${ }^{2}$ College of Materials Science and Engineering, Fujian University of Technical, Fuzhou, China \\ Email: ${ }^{*}$ pqdai@126.com
}

Received 20 August 2014; revised 5 October 2014; accepted 23 October 2014

Academic Editor: Hong Jin Kim, Advanced Module Engineering, Globalfoundries, USA

Copyright (C) 2014 by authors and Scientific Research Publishing Inc.

This work is licensed under the Creative Commons Attribution International License (CC BY). http://creativecommons.org/licenses/by/4.0/

(c) (i) Open Access

\begin{abstract}
The thermal stability of nanocrystalline Ni-Co-Fe-P coatings with phosphorus content up to 3.38 wt\% prepared by pulsed electrodepostion was studied using XRD, TEM and DSC. It is found that multi-component alloying does improve the thermal stability of nanocrystalline coatings due to a "solution drag effect". For nanocrystalline Ni-40.41\%Co-6.16\%Fe-1.63\%P coating, P-atoms segregate the grain boundaries during annealing which leads to a higher thermal stability. While due to the higher initial $\mathrm{P}$-concentration in $\mathrm{Ni}-30.1 \% \mathrm{Co}-2.15 \% \mathrm{Fe}-3.38 \% \mathrm{P}$, saturation of $\mathrm{P}$ and precipitation occurs earlier leading to a slightly lower stability.
\end{abstract}

\section{Keywords}

Nanocrystalline, Ni-Co-Fe-P Coatings, Thermal Stability, Activation Energy

\section{Introduction}

Due to their large interfacial volume fraction, nanocrystalline materials commonly have exceptional mechanical, magnetic, electrical, and corrosive properties. High hardness, corrosion resistance, and wear resistance make nanocrystalline materials as strong contenders for protective coating applications, replacing hard chromium layers which are harmful to the environment [1]. Technological application of nanocrystalline materials requires stability of the nanocrystalline microstructure at elevated temperatures which are often limited by grain growth.

Previous studies on the thermal stability of electrodeposited nanocrystals have shown that pure nanocrystalline materials are highly unstable with rapid grain growth occurring at relative low temperatures. Nanocrystal-

${ }^{*}$ Corresponding author. 
line $\mathrm{Ni}$ and $\mathrm{Co}$, for example, have onset temperatures for grain growth in the range of $220^{\circ} \mathrm{C}-310^{\circ} \mathrm{C}$ [2]-[5], while nanocrystalline $\mathrm{Al}, \mathrm{Sn}$ and $\mathrm{Mg}$ have all shown significant grain growth at room temperature [6] [7]. However, it is possible to design the starting nanocrystalline microstructure such that the material is more resistant to thermal induced grain growth-nanocrystalline Fe-Ni [8], Ni-Co [9], and Ni-P [10] coatings have higher thermal stability with respect to pure $\mathrm{Ni}$. It is thus evident that thermal stability of nanocrystalline metals could be improved by adding alloying elements.

Hence, the purpose of this study is to investigate the effect of multi-component alloying and solid solution element $\mathrm{P}$ additions on the thermal stability of nanocrystalline coatings. The evolution of texture and phase transformation behavior during the heating of nanocrystalline Ni-Co-Fe-P coatings would be discussed too.

\section{Experimental Procedures}

Nanocrystalline Ni-Co-Fe-P alloy coatings were electrodeposited by the pulsed current method onto copper cathodes from an electrolyte containing $\mathrm{Ni}\left(\mathrm{NH}_{2} \mathrm{SO}_{3}\right)_{2} \cdot 4 \mathrm{H}_{2} \mathrm{O}, \mathrm{NiCl}_{2} \cdot 6 \mathrm{H}_{2} \mathrm{O}, \mathrm{FeSO}_{4} \cdot 7 \mathrm{H}_{2} \mathrm{O}, \mathrm{CoSO}_{4} \cdot 6 \mathrm{H}_{2} \mathrm{O}, \mathrm{H}_{3} \mathrm{BO}_{3}$, $\mathrm{KCl}, \mathrm{C}_{6} \mathrm{H}_{5} \mathrm{Na}_{3} \mathrm{O}_{7}, \mathrm{CH}_{3}\left(\mathrm{CH}_{2}\right)_{11} \mathrm{OSO}_{3} \mathrm{Na}_{3} \mathrm{H}_{3} \mathrm{PO}_{3}$, saccharin, ascorbinc acid and 1, 4-butynediol to a thickness of $60 \sim 120 \mu \mathrm{m}$. The operation parameters for nanocrystalline coatings are shown in Table 1.

The compositions of coatings were determined using energy dispersive X-ray analysis (EDX), which was affiliated with the scanning electron microscope (SEM). All the chemical compositions of coatings are given in weight percent.

The as-deposited and annealing microstructures were characterized by X-ray diffraction (XRD) using $\mathrm{Cu} \mathrm{K} \alpha$ $(0.154056 \mathrm{~nm})$ radiation and by transmission electron microscopy (TEM) operating at $200 \mathrm{kV}$. The grain size of the coatings was calculated by using the Scherrer formula on the basis of the X-ray diffraction peak broadening.

Thermal stability of the specimens was examined by differential scanning calorimetry (DSC), where the samples were heated from room temperature up to $600^{\circ} \mathrm{C}$ at scanning rates of $10^{\circ} \mathrm{C} \cdot \mathrm{min}^{-1}, 20^{\circ} \mathrm{C} \cdot \mathrm{min}^{-1}, 30^{\circ} \mathrm{C} \cdot \mathrm{min}^{-1}$, $40^{\circ} \mathrm{C} \cdot \mathrm{min}^{-1}$. The activation energy for grain growth of nanocrystalline coatings was calculated by the Kissinger equation [11].

$$
\ln \left(\frac{B}{T_{p}^{2}}\right)=-\frac{E}{R T p}+C
$$

where $B$ is the heating rate, $T p$ is the peak temperation in DSC curse, $E$ is the activation energy of nanocrystalline coatings for the grain growth, $R$ is molar gas constant, and $C$ is constant.

\section{Results and Discussions}

\subsection{Microstructures of the As-Deposited Coatings}

XRD patterns of the as-deposited Ni-Co-Fe and Ni-Co-Fe-P coatings are shown in Figure 1. The structures of coatings are face-centered cubic (fcc) solid solutions, as revealed by both XRD and TEM observations. Line broadening in the diffraction patterns, which indicate considerable grain size reduction (Table 2), is observed with increasing $\mathrm{P}$ content in the as-deposited coatings. The grain size of the as-deposited coatings calculated by using the Scherrer formula is shown in Table 2. The grain size of the as-deposited coating is less than $10 \mathrm{~nm}$. The coatings are typical nanocrystalline coatings. X-ray diffraction patterns of nanocrystalline coatings in Figure 1 show strong (111) and weak (200) reflection peaks, which indicates that the coatings have a texture. It can be seen that the (200) peak intensity relative to the (111) peak increases with increasing $P$ in the coatings.

Figure 2 presents bright field TEM images and SAED patterns of the as-deposited $\mathrm{Ni}-45.05 \% \mathrm{Co}-14.48 \% \mathrm{Fe}$ and Ni-40.41\%Co-6.16\%Fe-1.63\%P alloy coatings. The samples show uniform nanocrystalline microstructure.

Table 1. Theoperation parameters for electrodepositing nanocrystalline Ni-Co-Fe-P coatings.

\begin{tabular}{ccc}
\hline & \multicolumn{2}{c}{ Parameters } \\
\cline { 2 - 3 } & Ni-Co-Fe coating & Ni-Co-Fe-P coating \\
\hline pH & 3.5 & 2 \\
Cathode currentdensity & $6 \mathrm{~A} / \mathrm{dm}^{2}$ & $2 \mathrm{~A} / \mathrm{dm}^{2}$ \\
Bath temperature & $45^{\circ} \mathrm{C}$ & $45^{\circ} \mathrm{C}$ \\
Duty cycle & $\mathrm{t}_{\text {on }}=4 \mathrm{~ms} \mathrm{t}_{\text {off }}=6 \mathrm{~ms}$ & $\mathrm{t}_{\text {on }}=7 \mathrm{~ms} \mathrm{t}_{\text {off }}=3 \mathrm{~ms}$ \\
Stir speed & $1300 \mathrm{r} / \mathrm{min}$ & $500 \mathrm{r} / \mathrm{min}$ \\
\hline
\end{tabular}




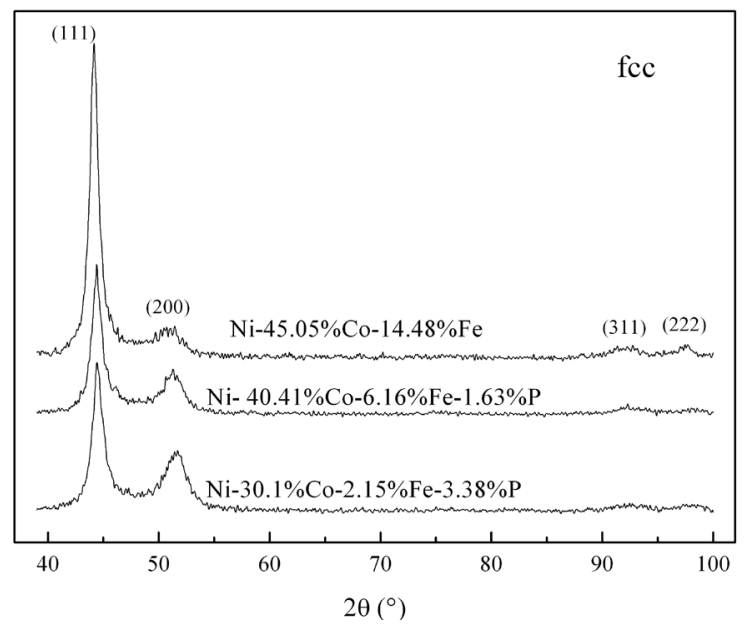

Figure 1. X-ray diffraction patterns of the as-deposited nanocrystalline coatings.

Table 2. The effect of annealing temperature on grain size of nanocrystalline coatings.

\begin{tabular}{cccc}
\hline Annealing & \multicolumn{2}{c}{ Grain size (nm) } \\
temperature $\left({ }^{\circ} \mathrm{C}\right)$ & $\mathrm{Ni}-45.05 \% \mathrm{Co}-14.48 \% \mathrm{Fe}$ & $\mathrm{Ni}-40.41 \% \mathrm{Co}-6.16 \% \mathrm{Fe}-1.63 \% \mathrm{P}$ & $\mathrm{Ni}-30.1 \% \mathrm{Co}-2.15 \% \mathrm{Fe}-3.38 \% \mathrm{P}$ \\
\hline As-deposited & 9.8 & 8.3 & 7.6 \\
$150^{\circ} \mathrm{C}$ & 10.4 & 9.5 & 7.9 \\
$375^{\circ} \mathrm{C}$ & 12.7 & 19.8 & 8.8 \\
$450^{\circ} \mathrm{C}$ & 75.1 & $>100$ & 29.5 \\
$600^{\circ} \mathrm{C}$ & $>100$ & & $>100$ \\
\hline
\end{tabular}

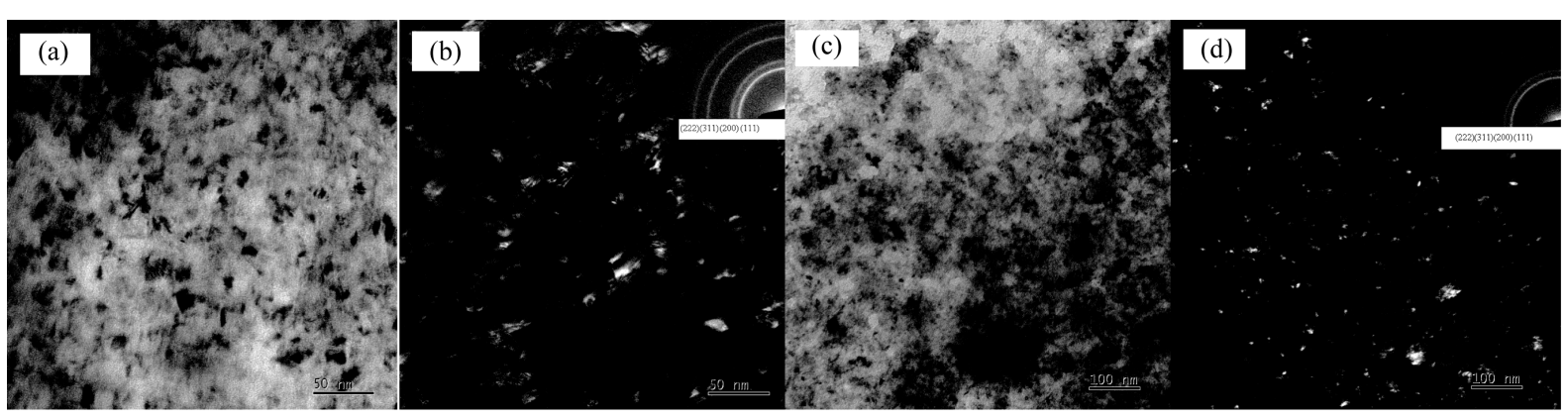

Figure 2. Example of a Bright, dark field TEM images and SAED patterns of nanocrystalline alloy coatings: (a) (b) Ni$45.05 \% \mathrm{Co}-14.48 \% \mathrm{Fe}$; (c) (d) Ni-40.41\%Co-6.16\%Fe-1.63\%P.

\subsection{Effects of Annealing on the Microstructure of the Coatings}

Figures 3(a)-(c) show X-ray diffraction patterns of nanocrystalline coatings annealed at various temperatures for $1 \mathrm{~h}$. In the samples annealed for $1 \mathrm{~h}$ up to $375^{\circ} \mathrm{C}$, the diffraction patterns are similar to that of the as-deposited sample with regard to XRD peak intensity and broadening. However, in the samples annealed above $450^{\circ} \mathrm{C}$ for $1 \mathrm{~h}$, the peak intensity drastically increased and the full width at half maximum of the peak significantly decreased. The latter indicates that the occurrence of grain growth in the annealing temperature range above $450^{\circ} \mathrm{C}$.

It can be seen that in the case of $\mathrm{Ni}-45.05 \% \mathrm{Co}-14.48 \% \mathrm{Fe}$ coating, the as-deposited sample and samples annealed below $375^{\circ} \mathrm{C}$ show a (111) texture, while the samples annealed above $450^{\circ} \mathrm{C}$ show a strong (111) texture. Therefore, it is evident that during annealing, the $<111>$ oriented grains grew faster than $<100>$ and other oriented grains. According to Li's calculation [12], the surface energy is the lowest for the $\{111\}$ plane and increases in the order of $\{100\},\{110\},\{311\},\{210\}$, etc.

During annealing the texture of nanocrystalline Ni-40.41\%Co-6.16\%Fe-1.63\%P deposit changed from $<111>$ to $<100>$. The texture change was attributed to preferential growth of $<100>$ grains at the expense of $<111>$ 

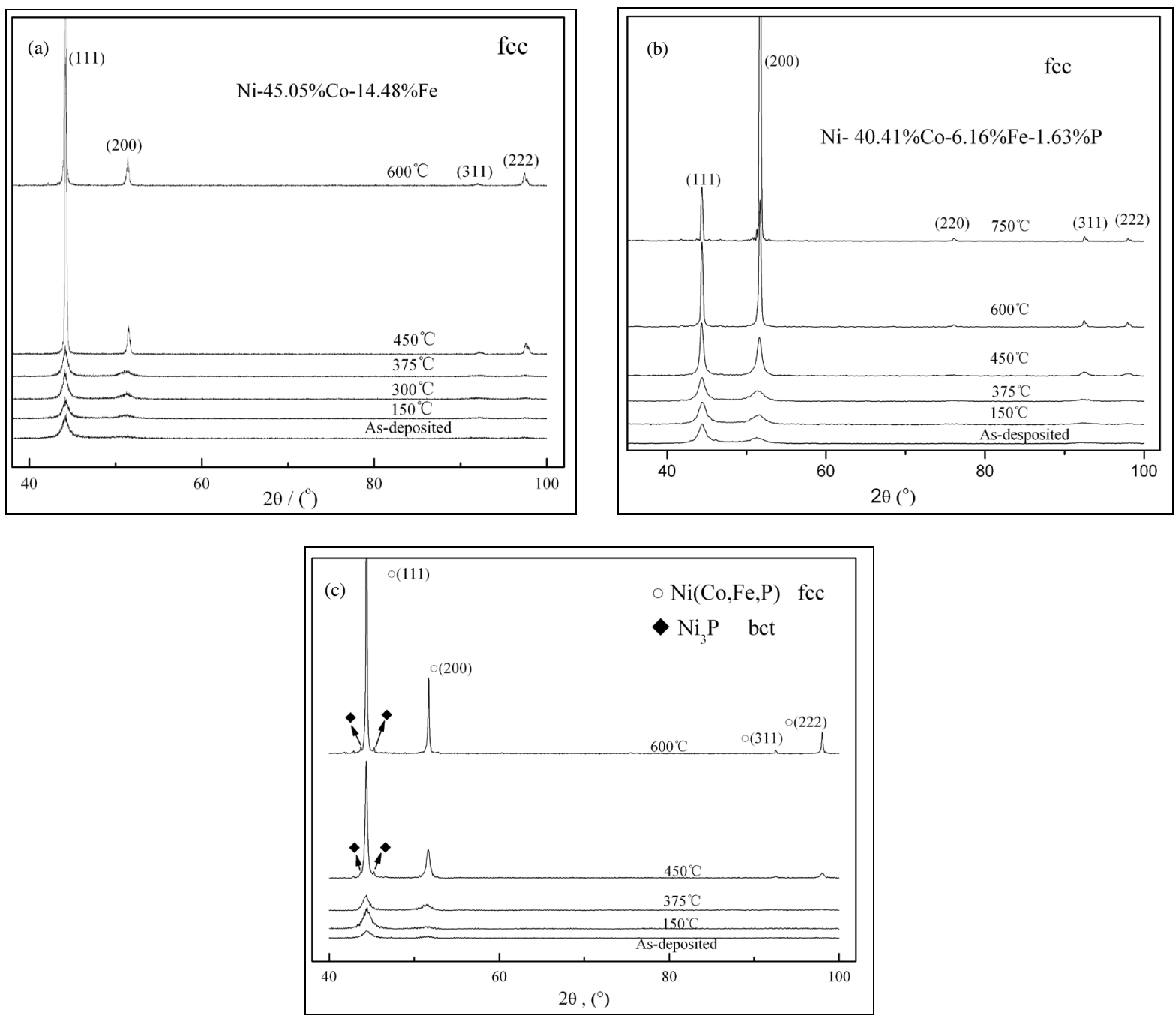

Figure 3. X-ray diffraction patterns of nanocrystalline coatings annealed at various temperatures for $1 \mathrm{~h}$. (a) $\mathrm{Ni}-45.05 \% \mathrm{Co}-$ $14.48 \% \mathrm{Fe}$; (b) Ni-40.41\%Co-6.16\%Fe-1.63\%P; (c) Ni-30.1\%Co-2.15\%Fe-3.38\%P.

grain to decrease the thermal strain energy of the deposit [13].

In the annealed specimens, the reflections of b.c.t. $\mathrm{Ni}_{3} \mathrm{P}$ phase are observed after annealing at $450^{\circ} \mathrm{C}$ or above for $1 \mathrm{~h}$ (Figure 3(c)). During annealing a transformation take place that follows the sequence: structural relaxation $\rightarrow$ P segregation $\rightarrow \mathrm{Ni}_{3} \mathrm{P}$ phase formation.

The grain size of the as-deposited and annealed coatings is shown in Table 2. No obvious grain growth of all three coatings was observed after annealing below $375^{\circ} \mathrm{C}$. The rapid grain growth takes place when annealing temperature rises up to $450^{\circ} \mathrm{C}$, however, the grain size is still less than $100 \mathrm{~nm}$. It indicates that all three nanocrystalline coatings have excellent thermal stability, and the Ni-40.41\%Co-6.16\%Fe- $1.63 \% \mathrm{P}$ is the best. The grain size of three coatings grows to be sub-micron grade after annealing above $600^{\circ} \mathrm{C}$.

\subsection{DSC Analysis of the Coatings}

The thermal stability of nanocrystalline coatings was characterized by DSC. Figure 4 presents calorimetry scans for each coating at a heating rate of $20^{\circ} \mathrm{C} \cdot \mathrm{min}^{-1}$. Take the Ni-45.05\%Co-14.48\%Fe coating for example, three different stages of grain growth were found: 1$)$ grain boundary relaxation $\left(120^{\circ} \mathrm{C}-430^{\circ} \mathrm{C}\right)$. Grain boundary relaxation and a little grain growth take place at this stage; this relaxation leads to positions of "low energy" for the grain boundaries creating first grown grains "accidently" by removing low angle grain boundaries; 2) abnormal grain growth $\left(430^{\circ} \mathrm{C}-500^{\circ} \mathrm{C}\right)$. The rapid grain growth occurs at this stage; 3 ) growth towards equili- 


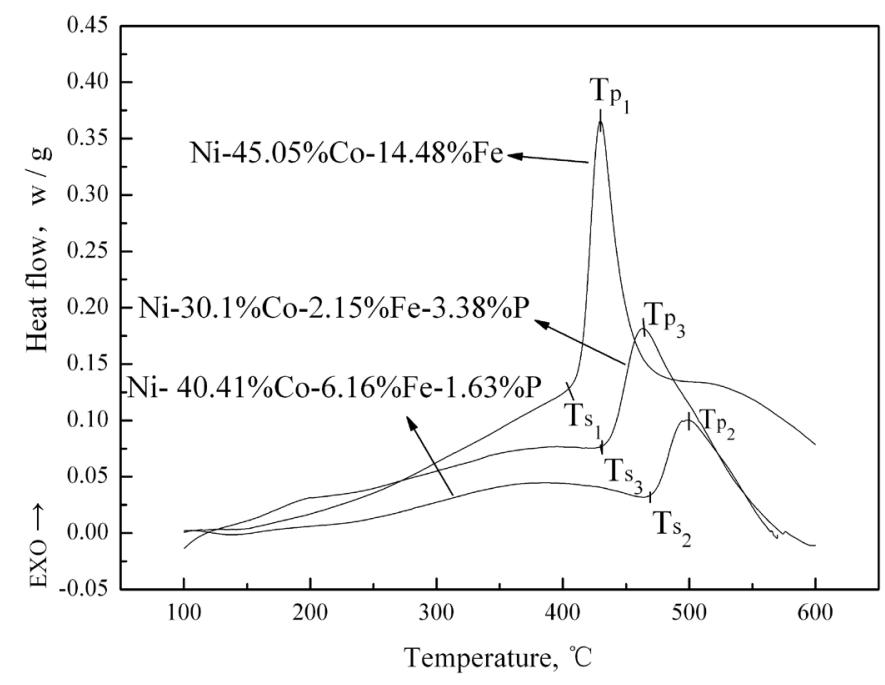

Figure 4. DSC-curves of nanocrystalline coatings (heating rate was $\left.20^{\circ} \mathrm{C} \cdot \mathrm{min}^{-1}\right)$.

brium (above $500^{\circ} \mathrm{C}$ ). Grain growth that comes about at this stage is dominated by lattice diffusion.

$T$ s presents the onset temperature of rapid grain growth. The peak temperature $(T p)$ is the point of maximal heat release on the DSC scan. They can be used as a relative indicator of thermal stability. The total enthalpy released during grain growth can be obtained by integrating the area under the curves and the values are summarized in Table 3. It can be found that the onset temperature and peak temperature of nanocrystalline Ni45.05\%Co-14.48\%Fe deposit is much higher than that of nanocrystalline Fe-Ni [8] and Ni-Co alloys [9]. The effect of multi-component alloying can be attributed to the change in the mobility of the grain boundaries by the solution drag mechanism [14].

A kinetic analysis of grain growth was obtained by scanning samples from each of the three coatings at multiple heating rates $\left(\mathrm{B}=10,20,40^{\circ} \mathrm{C} \cdot \mathrm{min}^{-1}\right)$. Ni-40.41\%Co-6.16\%Fe-1.63\%P exhibited the highest $T p$ values at each scanning rate. Values of $T s$ and $T p$ are summarized in Table 3 . The increase in $T p$ with scanning rate can be used to obtain activation energy of grain growth. Figure 5 presents a modified Kissinger plot; the activation energy is obtained from the slope of $\ln (B / T p)$ as a function of $1 / T p$. Activation energies of 229.59, 369.3 and $198.44 \mathrm{~kJ} \cdot \mathrm{mol}^{-1}$ are obtained for Ni-45.05\%Co-14.48\%Fe, Ni-40.41\%Co-6.16\%Fe-1.63\%P, and Ni-30.1\%Co$2.15 \% \mathrm{Fe}-3.38 \% \mathrm{P}$, respectively. It indicates that during annealing, $\mathrm{P}$-atoms segregate to the grain boundaries lead to a higher thermal stability. While saturation of $\mathrm{P}$ and precipitation occurs earlier leading to s slightly lower stability.

Mori et al. [15] calculated the relaxation time for the particle bearing boundary and is expressed as

$$
\tau=\tau_{\alpha} /\left(1+\frac{\pi d r}{\lambda^{2}}\right)
$$

Here $\lambda$ is the distance of particles, $r$ is the average radius of particles, $2 d$ presents the grain size, and is relaxation time of the particle-free boundary.

The grain growth of $\mathrm{Ni}_{3} \mathrm{P}$ phase takes place during annealing, leading to the decrescence of $\lambda$ and the augmentation of $r$ and $d$. According to the Equation (2), the relaxation time $(\tau)$ of nanocrystalline Ni-30.1\%Co2.15\%Fe-3.38\% $\mathrm{P}$ coating decreases because of the formation of $\mathrm{Ni}_{3} \mathrm{P}$.

\section{Conclusions}

Nanocrystalline Ni-Co-Fe-P alloy coatings have been prepared by pulsed electrodeposition. Their microstructural evolution during annealing, and the effect of multi-component alloying and solid solution $\mathrm{P}$ additions on the thermal stability of nanocrystalline coatings were investigated. The main results of this work are summarized below:

1) The as-deposited coatings exhibit only the fcc phase and a weak $\{111\}$ textures. 
Table 3. DSC analysis summary: onset temperature $T s$, peak temperature $T p$, enthalpy release $\Delta H$.

\begin{tabular}{cccccccccc}
\hline \multirow{2}{*}{$\begin{array}{c}\text { Heat } \\
\text { rate }\left({ }^{\circ} \mathrm{C} / \mathrm{min}\right)\end{array}$} & \multicolumn{3}{c}{$\mathrm{Ni}-45.05 \% \mathrm{Co}-14.48 \% \mathrm{Fe}$} & \multicolumn{2}{c}{$\mathrm{Ni}-40.41 \% \mathrm{Co}-6.16 \% \mathrm{Fe}-1.63 \% \mathrm{P}$} & \multicolumn{3}{c}{$\mathrm{Ni}-30.1 \% \mathrm{Co}-2.15 \% \mathrm{Fe}-3.38 \% \mathrm{P}$} \\
\cline { 2 - 9 } & $\mathrm{Ts}_{1}\left({ }^{\circ} \mathrm{C}\right)$ & $\mathrm{Tp}_{1}\left({ }^{\circ} \mathrm{C}\right)$ & $\Delta \mathrm{H}_{1}(\mathrm{~J} / \mathrm{g})$ & $\mathrm{Ts}_{2}\left({ }^{\circ} \mathrm{C}\right)$ & $\mathrm{Tp}_{2}\left({ }^{\circ} \mathrm{C}\right)$ & $\Delta \mathrm{H}_{2}(\mathrm{~J} / \mathrm{g})$ & $T s_{3}\left({ }^{\circ} \mathrm{C}\right)$ & $\mathrm{Tp}_{3}\left({ }^{\circ} \mathrm{C}\right)$ & $\Delta \mathrm{H}_{3}(\mathrm{~J} / \mathrm{g})$ \\
\hline 10 & 401.8 & 417.32 & 10.08 & 468.13 & 481.23 & 1.518 & 428.77 & 447.12 & 9.445 \\
20 & 414.82 & 429.32 & 18.37 & 475.76 & 493.76 & 5.094 & 438.01 & 464.03 & 20.61 \\
30 & 419.93 & 435.74 & 18.10 & - & - & - & - & - & - \\
40 & - & - & - & 475.13 & 497.31 & 6.128 & 447.27 & 476.28 & 16.29 \\
\hline
\end{tabular}

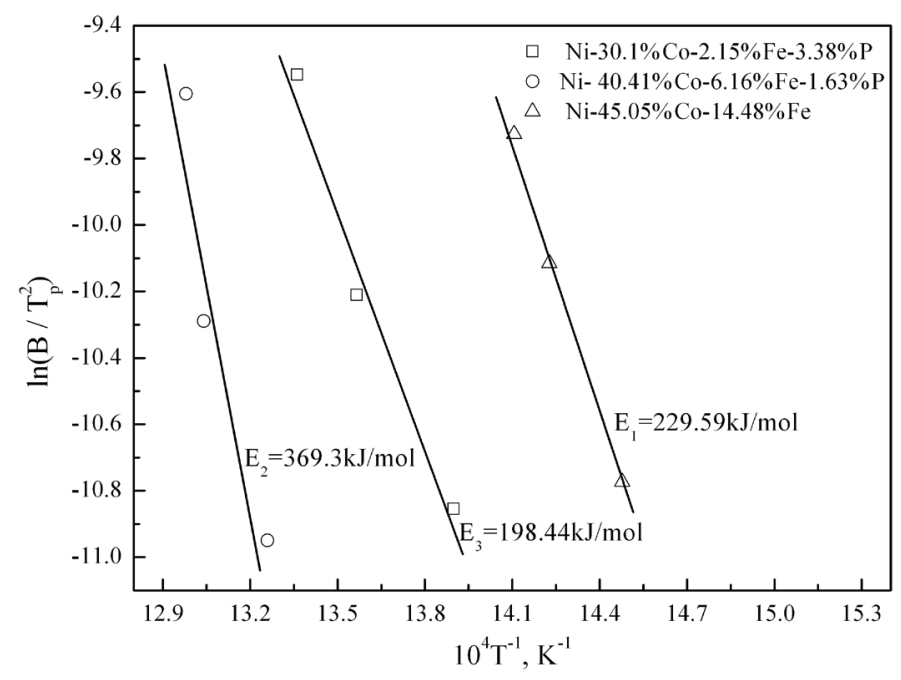

Figure 5. Kissinger's plot for grain growth in electrodeposited nanocrystalline Ni-Co-Fe-P coatings.

2) The microstructural evolution of nanocrystalline coatings takes place during annealing. The nanocrystalline $\mathrm{Ni}-45.05 \% \mathrm{Co}-14.48 \% \mathrm{Fe}$ and $\mathrm{Ni}-40.41 \% \mathrm{Co}-6.16 \% \mathrm{Fe}-1.63 \% \mathrm{P}$ coatings show a strong (111) texture during annealing. The texture of nanocrystalline Ni-40.41\%Co-6.16\%Fe-1.63\%P coating changed from $<111>$ to $<100>$ during annealing.

3) Multi-component alloying promoted the thermal stability of nanocrystalline alloy due to a "solute drag effect”. For nanocrystalline Ni-40.41\%Co-6.16\%Fe-1.63\%P deposit, P-atoms segregate the grain boundaries during annealing which leads to a higher thermal stability. While due to the higher initial P-concentration in Ni$30.1 \% \mathrm{Co}-2.15 \% \mathrm{Fe}-3.38 \% \mathrm{P}$, saturation of $\mathrm{P}$ and precipitation occurs earlier leading to a slightly lower stability.

\section{Acknowledgements}

This project was supported by the Natural Science Foundation of Fujian Province (Grant No. 2012J01202 ) and the Education Department of Fujan Province (Grant No. JA11179).

\section{References}

[1] Su, F.H., Liu, C.S. and Huang, P. (2013) Friction and Wear of Nanocrystalline Co and Co-W Alloy Coatings Produced by Pulse Reverse Electrodeposition. Wear, 300, 114-125. http://dx.doi.org/10.1016/j.wear.2013.01.120

[2] Hibbard, G., Erb, U., Aust, K.T., et al. (2002) Thermal Stability of Nanostrctured Coatings. Materials Science Forum, 386-388, 387-396. http://dx.doi.org/10.4028/www.scientific.net/MSF.386-388.387

[3] Hibbard, G., Aust, K.T., Palumbo, G., et al. (2001) Thermal Stability of Electrodeposited Nanocrystalline Cobalt. Scripta Materialia, 44, 513-518. http://dx.doi.org/10.1016/S1359-6462(00)00628-X

[4] Yu, H. and Dai, P.Q. (2004) Thermal Stability of Pulsed Electrodeposited Nanocrystalline Ni. Heat Treatment of Metals, 30, 16-18.

[5] Klement, U., Erb, U. and Elsherik, A.M. (1995) Thermal Stability of Nanocrystalline Ni. Materials Science and Engi- 
neering A, 203, 177-186. http://dx.doi.org/10.1016/0921-5093(95)09864-X

[6] Malow, T.R. and Koch, C.C. (1996) Thermal Stability of Nanocrystalline Materials. Materials Science Forum, 225227, 595-604. http://dx.doi.org/10.4028/www.scientific.net/MSF.225-227.595

[7] Birringer, R. (1989) Nanocrystalline Materials. Materials Science and Engineering A, 117, 33-43. http://dx.doi.org/10.1016/0921-5093(89)90083-X

[8] Liu, Y.C., Liu, L., Shen, B., et al. (2011) A Study of Thermal Stability in Electrodeposited Nanocrystalline Fe-Ni Invar Alloy. Materials Science and Engineering A, 528, 5701-5705. http://dx.doi.org/10.1016/j.msea.2011.04.052

[9] Hibbard, G.D., Aust, K.T. and Erb, U. (2006) Thermal Stability of Electrodeposited Nanocrystalline Ni-Co Alloys. Materials Science and Engineering A, 433, 195-202. http://dx.doi.org/10.1016/j.msea.2006.06.096

[10] Shigeaki, K. and Youhei, K. (2003) Grain Growth and Mechanical Properties of Electrodeposited Nanocrystalline Nickel-4.4Mass\% Phosphorus Alloy. Materials Science and Engineering A, 358, 76-83. http://dx.doi.org/10.1016/S0921-5093(03)00285-5

[11] Kissinger, H.E. (1957) Reaction Kinetics in Differential Thermal Analysis. Analytical Chemistry, 29, 1672-1706. http://dx.doi.org/10.1021/ac60131a045

[12] Humphreys, F.J. and Hatherly, M. (1995) Recrystallization and Related Annealing Phenomena. Elsevier Science Ltd., Oxford.

[13] Lee, D.N. and Hur, K.H. (1999) The Evolution of Texture during Annealing of Electroless Ni-Co-P Coatings. Scripta Materialia, 40, 1333-1339. http://dx.doi.org/10.1016/S1359-6462(99)00105-0

[14] Humphrey, F.J. and Hatherly, M. (1996) Recrystallization and Related Annealing Phenomena. Pergamon Press, Oxford.

[15] Mori, T., Koda, M., Monzen, R., et al. (1983) Particle Blocking in Grain Boundary Sliding and Associated Internal Friction. Acta Metallurgica, 31, 275-283. http://dx.doi.org/10.1016/0001-6160(83)90104-9 
Scientific Research Publishing (SCIRP) is one of the largest Open Access journal publishers. It is currently publishing more than 200 open access, online, peer-reviewed journals covering a wide range of academic disciplines. SCIRP serves the worldwide academic communities and contributes to the progress and application of science with its publication.

Other selected journals from SCIRP are listed as below. Submit your manuscript to us via either submit@scirp.org or Online Submission Portal.
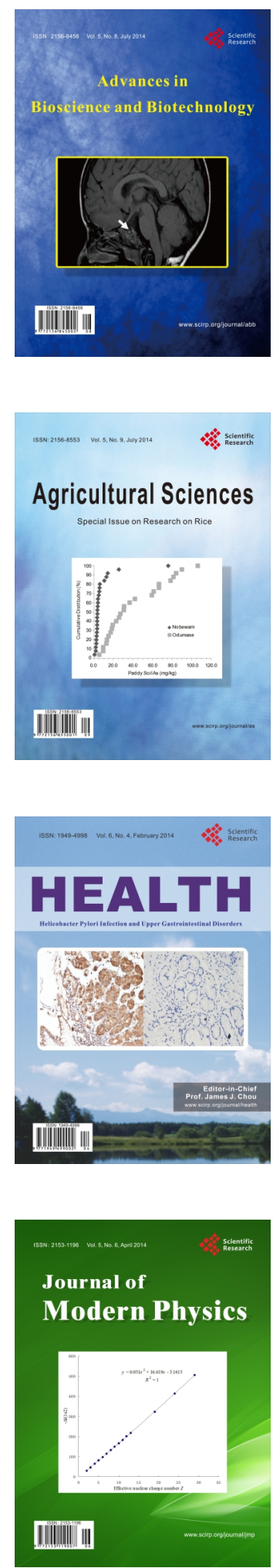
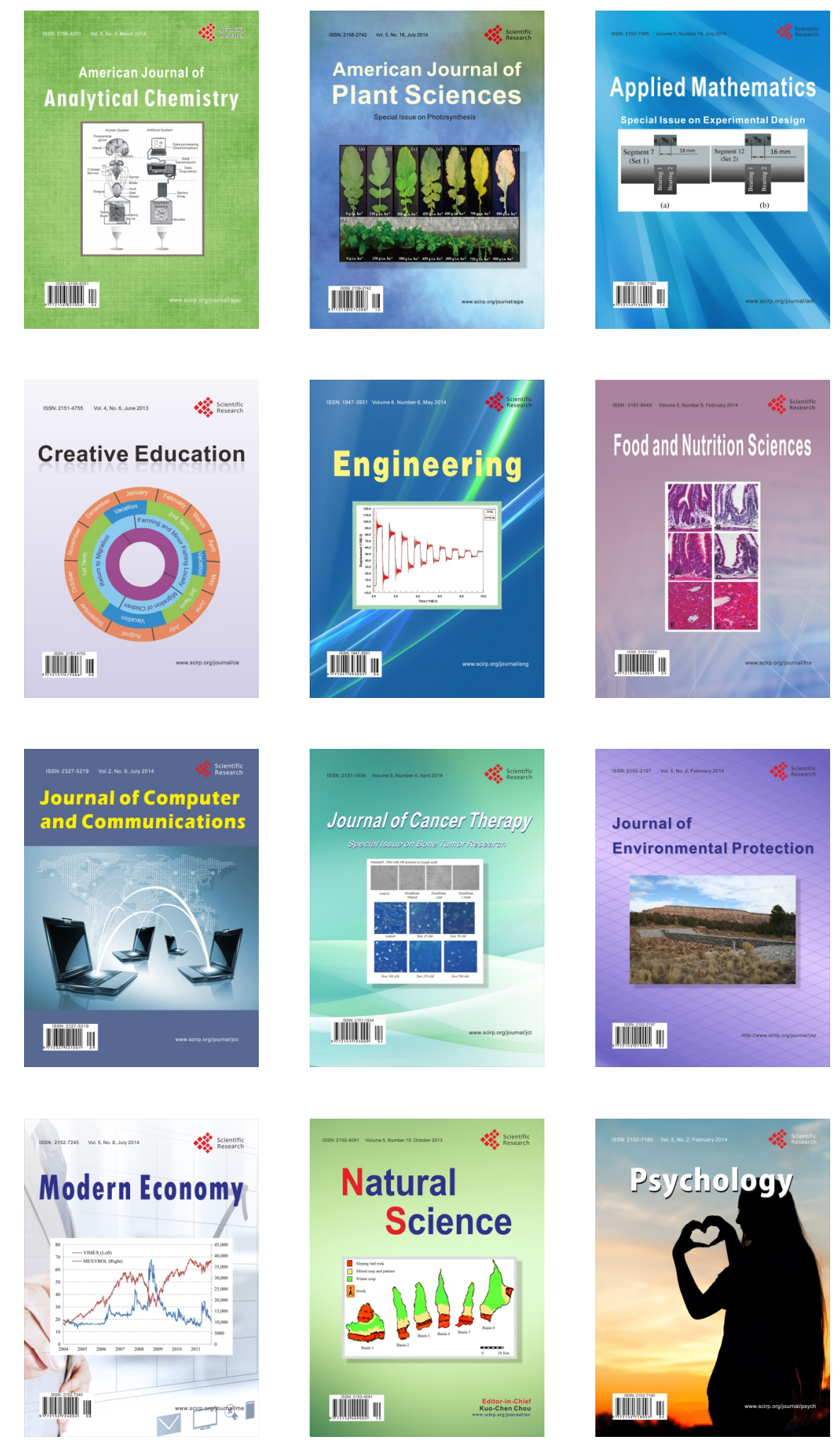